\title{
A permanência de estudantes com deficiência nas universidades brasileiras ${ }^{1}$
}

\section{The permanence of students with deficiency in Brazilian universities}

\author{
Carina Elisabeth Maciel* \\ Alexandra Ayach Anache*
}

\begin{abstract}
RESUMO
O presente texto tem como objetivo analisar o Programa Incluir - Acessibilidade na Educação Superior como estratégia de permanência da pessoa com deficiência na educação superior. O Programa Incluir foi criado em 2005 e tem o "[...] objetivo de promover ações para eliminar barreiras físicas, pedagógicas e de comunicação, a fim de assegurar o acesso e a permanência de pessoas com deficiência nas instituições federais de educação superior (IFEs)" (BRASIL, 2013). A metodologia utilizada no texto foi análise documental e bibliográfica. Os dados analisados indicam que o Programa Incluir vem sendo uma das possibilidades para favorecer a permanência de estudantes, público-alvo da Educação Especial, desenvolvendo seus estudos na educação superior.
\end{abstract}

Palavras-chave: Educação Especial. Educação superior. Políticas públicas. Programa Incluir.

\footnotetext{
ABSTRACT

The following text has as objective to analyze the Programa Incluir Acessibilidade na Educação Superior as a strategy of permanence of people

DOI: $10.1590 / 0104-4060.52924$

1 Trabalho apresentado no XXIII Seminário Nacional da Rede Universitas/BR - políticas de educação superior no Brasil: a expansão privado-mercantil em questão - Eixo 5 - Acesso e permanência na expansão da educação superior, realizado no período de 20 a 23 de março de 2015, Universidade Federal do Pará. Instituto de Ciências da Educação. Belém: ICED/UFPA, 2015. p.

* Universidade Federal de Mato Grosso do Sul (UFMS). Campo Grande, Mato Grosso do Sul, Brasil. Cidade Universitária, s/nº Caixa-postal: 549. CEP: 79070-900. E-mail: carina22em@ gmail.com; alexandra.anache@gmail.com
} 798-814. 
with deficiency in superior education. The Programa Incluir was created in 2005 and has the "[...] objective to promote actions to eliminate physical, pedagogic and communicational barriers, to assure the access and the permanence of people with deficiency in the Federal Institutions of Superior Education (IFEs)" (BRAZIL, 2013). The methodology used in the text was a documental and bibliographic analysis. The analyzed data indicates that the Programa Incluir has been being one of the possibilities to favorize the permanence of students, target public of special education, developing their studies in the superior education.

Keywords: Special Education. Superior education. Public politics. Programa Incluir.

\section{Introdução}

Pesquisar as políticas públicas de inclusão na educação superior é compreender uma ação política no sentido de questionar se o acesso à educação, como um direito humano, está sendo respeitado; pois o processo educativo no contexto atual conjuga igualdade e diferença como valores indissociáveis e avança em relação à ideia de garantia de direitos básicos ao contextualizar as circunstâncias históricas da produção da exclusão dentro e fora do sistema educacional. Assim, o presente texto tem como objetivo apresentar o Programa Incluir como estratégia de permanência da pessoa com deficiência na educação superior. Para entender essa temática, foi também necessário um estudo sobre a reforma do Estado capitalista e seus desdobramentos, que interferem nas políticas sociais e também nas políticas educacionais que são desenvolvidas no país.

O Programa Incluir - Acessibilidade na Educação Superior foi criado em 2005 e tem o "[...] objetivo de promover ações para eliminar barreiras físicas, pedagógicas e de comunicação, a fim de assegurar o acesso e a permanência de pessoas com deficiência nas instituições federais de educação superior (IFEs)" (BRASIL, 2013). Foi desenvolvido pela Secretaria de Educação Superior (SESU) em parceria com a Secretaria de Educação Especial (SEESP) e é voltado para inclusão de pessoas com deficiência na educação superior, em cumprimento ao Decreto $\mathrm{n}^{\circ}$ 5.296/2004. (BRASIL, 2004).

O Programa Incluir é uma ação afirmativa a favor da inclusão na educação superior da pessoa com deficiência, financiando projetos com vistas a romper o contexto de exclusão na busca por uma educação de qualidade. Além disso, pretende beneficiar a população que apresenta deficiência nas instituições federais 
de educação (IFEs) e também fomentar a criação e a consolidação de Núcleos de Acessibilidade. (BRASIL, 2013). Os Núcleos de Acessibilidade respondem pela organização de ações institucionais que garantam a integração de pessoas com deficiência à vida acadêmica, eliminando barreiras comportamentais, pedagógicas, arquitetônicas e de comunicação.

A metodologia utilizada no texto foi análise documental e bibliográfica e torna-se relevante, com vistas a analisar as políticas públicas de inclusão na educação superior, neste início de século, principalmente na gestão do Governo de Luiz Inácio Lula da Silva e do Governo de Dilma Rousseff, que se apresentam com discursos de promover a participação popular e transformação da sociedade com vistas à inclusão. Esses governos trataram de criar condições para a sustentação financeira dos estabelecimentos já existentes e criaram uma série de programas para a ampliação do acesso e da permanência na educação superior.

$\mathrm{O}$ texto está organizado em três tópicos. No primeiro tópico, discorremos sobre o Estado capitalista e seu papel na formulação das políticas educacionais. No segundo, apresentamos as políticas públicas de inclusão na educação superior e, no terceiro, falamos sobre o Programa Incluir como estratégia de permanência da pessoa com deficiência na educação superior.

\section{O Estado capitalista e seu papel na formulação das políticas educacionais}

Para entender a temática do texto, é necessário também um estudo sobre a reforma do Estado capitalista e seus desdobramentos. Estes interferem nas políticas sociais e também nas políticas educacionais que são implantadas no país.

Para Bittar e Morosini (2006, p. 165), as políticas sociais são “ações que determinam o padrão de proteção social implementado pelo Estado, voltadas, em princípio, à redistribuição dos benefícios sociais. [...] abrangendo ações nas áreas da saúde, previdência e assistência social, cultura, comunicação e educação [...]". Já as políticas educacionais são "políticas sociais inseridas no espaço teórico-analítico das políticas públicas, que representam a materialidade da intervenção do Estado [...]".

Dessa forma, compreende-se que os estudos em Ciências Sociais são dependentes das grandes questões de cada época e limitados pela realidade do desenvolvimento social. Exemplo de uma grande questão política, econômica e social é o neoliberalismo, porque representa a própria sociedade transformada 
pelo movimento de um sistema econômico que provocou grande exclusão das classes sociais menos favorecidas no mundo todo.

Segundo Bianchetti (2005, p. 21), as três últimas décadas do século XX foram importantes para consolidar a hegemonia neoliberal como um novo modelo de sociedade no mundo ocidental. No entanto, "não se pode correr o risco de tomar uma definição reducionista para compreender esse modelo". O autor afirma que:

Em geral, os autores que analisam essa temática a definem como um movimento político-econômico heterogêneo consolidado nos países capitalistas desenvolvidos, em meados da década de 70, cuja proposta econômica significa o retorno aos princípios ortodoxos do liberalismo, ou seja, às propostas da economia clássica como única alternativa de superação da crise pela qual passam essas sociedades. (BIANCHETTI, 2005, p. 21).

No entanto, mesmo que o neoliberalismo seja um movimento que tenha como estratégia mundial o enfrentamento da crise que o capitalismo apresenta, por meio da redefinição do papel do Estado pelo retorno aos ideais clássicos do liberalismo, não é conveniente considerá-lo como uma tendência do pensamento liberal. Porém, é necessário retomar as ideias do liberalismo, que se apresentam nos mecanismos naturais de mercado, dessa forma, foram induzidos pela aplicação de políticas redistributivas, direcionadas pelo Estado, para se entender como se chegou ao modelo neoliberal.

Para Hayek, a tendência geral do desenvolvimento social era libertar os indivíduos de exceções que os mantinham cativos a determinados padrões ou costumes. Essa libertação ocorreu num lento processo histórico, que o autor resume como: “[...] a transformação gradual de um sistema hierárquico organizado em moldes rígidos num sistema em que os homens podiam pelo menos tentar dirigir a própria vida [...] está intimamente ligada ao desenvolvimento do comércio" (HAYEK, 1994, p. 41).

O resultado dessa ação de franca ampliação das atividades econômicas foi um crescimento além do esperado. A ampliação do livre comércio trouxe ao homem a liberdade individual e econômica. Esse ideário político se estendeu por toda a Europa e, como resultado da política de liberdade, o homem foi conquistando melhorias materiais e grandes probabilidades de progresso.

Sob esse aspecto do pensamento liberal, Bobbio (2005, p. 21) afirma: 
Uma vez definida a liberdade no sentido predominante da doutrina liberal como liberdade em relação ao Estado, o processo de formação do Estado liberal pode ser identificado com o progressivo alargamento da esfera de liberdade do indivíduo, diante dos poderes públicos (para usar os termos de Paine), com a progressiva emancipação da sociedade ou da sociedade civil, no sentido hegeliano e marxiano, em relação ao Estado.

Analisada por essa ótica, a palavra liberdade passa a ser sinônimo de poder ou de riqueza. Seguindo os novos rumos que a história tomava, Hayek coloca que a promessa de liberdade atraiu um grande número de liberais para o socialismo. Mas essa convicção apenas intensificaria a tragédia se ficasse demonstrado que aquilo que nos prometiam como "Caminho da Liberdade" era na realidade o "Caminho da Servidão". E acrescenta, "[...] não obstante os termos 'capitalismo' e 'socialismo' ainda serem usados, em geral, para designar respectivamente as formas passada e futura da sociedade, eles ocultam a natureza da transição que vivemos ao invés de elucidá-la" (HAYEK, 1994, p. 61). No entanto, nesse modelo de liberdade, o indivíduo se livraria da miséria, da força das conjunturas que confinam a área de preferência, do "despotismo da necessidade material" e seriam suavizadas "as restrições decorrentes do sistema econômico" (HAYEK, 1994, p. 49).

Isso mostrou que a teoria econômica desenvolvida por Keynes, que sustentaria o modelo do Estado Benfeitor a partir da chamada Grande Depressão, mantendo que o Estado deve intervir na economia de mercado com o fim de diminuir o desemprego involuntário e aumentar a produção (BIANCHETTI, 2005 , p. 24), foi incapaz de apresentar soluções para a crise. Esse foi um dos passos que contribuíram para o processo evolutivo do novo pensamento liberal.

Concernente à política educacional para a educação superior brasileira, $\mathrm{o}$ que está previsto na Constituição Federal Brasileira de 1988, no art. 208, inc. $\mathrm{V}$, é que "o acesso aos níveis mais elevados do ensino, da pesquisa e da criação artística se dará segundo a capacidade de cada um" (BRASIL, 1988). Portanto, é dever do Estado garantir a educação, mas o nível superior fica condicionado ao preparo intelectual de cada indivíduo.

Mesmo que se construam diferentes maneiras de alcançar uma igualdade material, com potencial para vencer as diferenças discricionárias, e que possam seguramente propiciar as pessoas chances de ter oportunidades semelhantes, existem grupos historicamente discriminados na sociedade que dependem das políticas públicas para terem acesso a bens, como o acesso à educação superior pelas pessoas com deficiência. 


\section{As políticas públicas de inclusão na educação superior}

As políticas públicas de inclusão na educação superior assumem espaço central no debate sobre o papel da universidade pública na superação da lógica da exclusão, histórica nesse país. A universidade pública vem passando por mudanças estruturais e políticas; uma das alterações acontece para que as pessoas possam ter acesso à universidade e que suas necessidades de permanência sejam atendidas.

Já existem no cenário educacional mundial, vários acordos e documentos direcionados a minimizar a exclusão na educação superior, como os promovidos pela Organização das Nações Unidas para a Educação, a Ciência e a Cultura (UNESCO): a Conferência de Educação para Todos em 1990; a Conferência Mundial sobre Necessidades Educativas Especiais - Acesso e Qualidade, Salamanca, em 1994; o Fórum Mundial de Educação 803 em 2001; e a Conferência Mundial sobre Educação Superior em 2009; e, pela Organização das Nações Unidas (ONU), a Convenção sobre os Direitos da Pessoa com Deficiência em 2006. No cenário educacional brasileiro, a inclusão está amparada na Lei de Diretrizes e Bases da Educação Nacional (LDB), Lei Federal nº 9.394/1996; no Plano Nacional de Educação, aprovado pela Lei n ${ }^{\circ}$ 10.192/2001, e nas Diretrizes da Educação Especial na Educação Básica, por meio da Resolução CNE/CEB n ${ }^{\circ}$ 2/2001, e na Política Nacional de Educação Especial na Perspectiva da Educação Inclusiva (PNEEPE), aprovada em 2008, pelo Decreto do Legislativo no ${ }^{\circ}$ 186/2008.

A Declaração dos Direitos Humanos de 1948 veio garantir o direito de que todos tenham educação pública. Esse documento contribuiu intensamente para a criação dos serviços de Educação Especial e classes especiais em escolas públicas no Brasil. Surge, dessa forma, uma política nacional de educação, ancorada na Lei $n^{\circ}$ 4.024/1961 (Lei de Diretrizes e Bases da Educação Nacional - LDB), com a recomendação de integrar, no sistema geral de ensino, a educação de pessoas com deficiências.

Na LDB n ${ }^{\circ} 9.394 / 1996$, estão estabelecidas as diretrizes e bases da educação nacional. $\mathrm{O}$ capítulo $\mathrm{V}$ foi dedicado à Educação Especial e diz que a educação de pessoas com deficiência deve ocorrer de preferência na rede regular de ensino. Isso nos dá um novo direcionamento na forma de entender como ofertar educação para essas pessoas.

$\mathrm{O}$ art. 59 preconiza que os sistemas de ensino devem assegurar aos alunos currículo, métodos, recursos e organização específicos para atender às suas necessidades. Além disso, assegura terminalidade específica àqueles que não atingiram o nível exigido para a conclusão do ensino fundamental, em virtude das suas deficiências, e a aceleração de estudos aos superdotados para a conclusão 
do programa escolar. Também define, dentre as normas para a organização da educação básica, a "possibilidade de avanço nos cursos e nas séries mediante verificação do aprendizado" (BRASIL, 1996, art. 2 $2^{\circ}$ inciso V) e "[...] oportunidades educacionais apropriadas, consideradas as características do alunado, seus interesses, condições de vida e de trabalho, mediante cursos e exames" (BRASIL, 1996, art. 37).

Em 1999, o Decreto $n^{\circ} 3.298$, que regulamenta a Lei $n^{\circ} 7.853 / 1989$, ao dispor sobre Política Nacional para a integração de pessoa com deficiência, define a Educação Especial como uma modalidade transversal a todos os níveis e modalidades de ensino.

A Convenção da Guatemala (1999), promulgada no Brasil pelo Decreto $n^{0} 3.956 / 2001$, afirma que as pessoas com deficiência têm os mesmos direitos humanos e liberdades fundamentais que as demais pessoas, definindo como discriminação, com base na deficiência, toda diferenciação ou exclusão que possa impedir ou anular o exercício dos 804 direitos humanos e de suas liberdades fundamentais. Esse decreto tem importante repercussão na educação, exigindo uma reinterpretação da Educação Especial, compreendida no contexto da diferenciação adotada para promover a eliminação das barreiras que impedem o acesso aos níveis mais avançados da escolarização. (BRASIL, 2001a).

Acompanhando o processo de mudanças, as Diretrizes Nacionais para a Educação Especial na Educação Básica, Resolução CNE/CEB nº 2/01, no art. $2^{\circ}$, determinam que:

Os sistemas de ensino devem matricular todos os alunos, cabendo às escolas organizar - se para o atendimento aos educandos com necessidades educacionais especiais, assegurando condições necessárias para uma educação de qualidade para todos. (BRASIL, 2001c).

O Plano Nacional de Educação (PNE), Lei n ${ }^{0}$ 10.172/2001, destaca que "o grande avanço que a década da educação deveria produzir seria a construção de uma escola inclusiva que garanta o atendimento à diversidade humana" (BRASIL, 2001b). O movimento a favor da inclusão escolar pressupõe a escolarização dos alunos com deficiência através de práticas que respeitem as diferenças individuais nas escolas comuns.

Em 2003, o Governo Luiz Inácio Lula da Silva criou o Programa Universidade para Todos (ProUni) que, segundo Carvalho (2010), se trata de tornar pública vagas privadas para enfrentar, ainda que parcialmente, o problema da limitação do acesso à educação superior e garantir mais igualmente de oportunidades para a 
população. O governo também criou e consolidou 42 campi e o MEC autorizou a contratação de 5.000 professores, sendo 4.000 para docentes da educação superior. Em 13 de janeiro de 2005, o ProUni foi transformado na Lei no 11.096/2005.

Em 14 de abril de 2004, o governo criou o Sistema Nacional de Avaliação da Educação Superior (SINAES), instituído pela Lei n ${ }^{\circ} 10.861$, com o objetivo de conduzir o processo de avaliação da educação superior. O programa está assentado no seguinte tripé: avaliação das instituições da educação superior, dos cursos de graduação e do desempenho dos estudantes. É pelo SINAES que as instituições de educação superior são credenciadas, obtém autorização e reconhecimento para o oferecimento dos seus cursos de graduação, além da renovação periódica da oferta desses cursos. (CARVALHO, 2010).

Em 2 de dezembro de 2004, o governo criou a Lei de Inovação Tecnológica (Lei $\left.{ }^{\circ} 10.973\right)$, que dispõe sobre incentivos à inovação e à pesquisa científica e tecnológica no ambiente produtivo. Segundo essa lei, o montante principal das verbas de pesquisa será repassado às universidades. Ainda no ano de 2004, o governo cria a Lei n ${ }^{\circ} 11.079$, que instituiu normas gerais para licitação e contratação de Parcerias Público-Privada (PPP) no âmbito da administração pública. O governo também implementou mudanças jurídico-normativas mediante a adição de outros decretos e uma portaria interministerial: o Decreto $\mathrm{n}^{0} 5.154$, de 20 de julho, que regulamenta a oferta de educação profissional tecnológica de graduação e faz articulação entre os ensinos médio e técnico.

Foram vários os decretos que o Governo Lula assinou, no ano de 2004, o Decreto $n^{\circ} 5225$, de $1^{\circ}$ de outubro de 2004, que elevou os Centros Federais de Educação Tecnológica (CEFET) - escolas tradicionais de nível médio - à categoria de instituições de educação superior. Os cursos tecnológicos, que eram cursos superiores diferenciados dos de graduação, adquiriram o status de cursos de graduação e pós-graduação. O Decreto $\mathrm{n}^{\circ} 5.254$, de $1^{\circ}$ de outubro de 2004, dispôs sobre a organização dos CEFETs, as principais escolas de educação do país. O Decreto-Lei $n^{\circ} 5.296$ - que regulamenta as Leis $n^{\circ} 10.048 / 2000$ e $n^{\circ}$ 10.098/2000 -, art. 227, § $2^{\circ}$, e a Constituição Federal, art. 244, para cumprir este Decreto, o governo criou o Programa de Acesso a Universidade (Incluir), voltado exclusivamente para as instituições públicas federais de educação superior.

Em 29 de dezembro de 2005, o governo assinou o Decreto $n^{0} 5.622$, regulamentando a oferta de educação a distância na educação superior, no sentido de que a ampliação da oferta de vagas ocorra, também, por meio dessa modalidade e não da abertura de novos cursos de graduação nas instituições públicas.

Ainda em 2005, o MEC propôs a criação de programas de políticas sob a perspectiva da inclusão na educação superior, dando destaque ao Programa Incluir - Acessibilidade na Educação Superior. O Programa Incluir foi desenvolvido pela Secretaria de Ensino Superior (SESU) em parceria com a Secretaria de Educação 
Especial (SEESP). O programa é voltado para a inclusão de pessoas com deficiência na educação superior em cumprimento ao Decreto no 5.296/2004. (BRASIL, 2004). No Governo de Dilma Rousseff, a parceria é realizada por meio da Secretaria de Educação Superior (SESU) e da Secretaria de Educação Continuada, Alfabetização, Diversidade e Inclusão (SECADI). Já em 2006 foi assinado o Decreto $\mathrm{n}^{\circ}$ 5.773, que estabelece normas para as funções de regulação, supervisão e avaliação das instituições de educação superior, e o Projeto de Lei $n^{\circ} 7.200 / 2006$, que estabelece nova regulamentação para a educação superior brasileira.

Foi lançado oficialmente, em 24 de abril de 2007, o Plano de Desenvolvimento da Educação (PDE), que trata dos objetivos e das ações para os diferentes níveis e modalidades da educação brasileira. O PDE da educação superior elege os seguintes princípios: expansão da oferta de vagas; garantia de qualidade, promoção de inclusão social, ordenação territorial; desenvolvimento econômico e social. Nele, o Programa de Apoio aos Planos de Reestruturação e Expansão das Universidades Federais (REUNI) e o Plano Nacional de Assistência Estudantil (PNAES) são programas considerados próprios para atingir tais objetivos.

O Programa de Apoio a Planos de Reestruturação e Expansão das Universidades Federais (Reuni) tem como principal objetivo ampliar o acesso e a permanência na educação superior. Com o Reuni, o governo federal adotou uma série de medidas para retomar o crescimento da educação superior pública, criando condições para que as universidades federais promovam a expansão física, acadêmica e pedagógica da rede federal. O Plano Nacional de Assistência Estudantil (PNAES) apoia a permanência de estudantes de baixa renda matriculados em cursos de graduação presencial das instituições federais de educação superior (IFES). O objetivo é viabilizar a igualdade de oportunidades entre todos os estudantes e contribuir para a melhoria do desempenho acadêmico, a partir de medidas que buscam combater situações de repetência e evasão.

O PNAES oferece assistência à moradia estudantil, alimentação, transporte, à saúde, inclusão digital, cultura, esporte, creche e apoio pedagógico. As ações são executadas pela própria instituição de ensino, que deve acompanhar e avaliar o desenvolvimento do programa. Os critérios de seleção dos estudantes levam em conta o perfil socioeconômico dos alunos, além de critérios estabelecidos de acordo com a realidade de cada instituição. Criado em 2008, através do Decreto $\mathrm{n}^{\mathrm{o}} 7.234$, de 19 de julho de 2010, o programa recebeu, no seu primeiro ano, R\$ 125,3 milhões em investimentos. Em 2009, foram R \$203,8 milhões investidos diretamente no orçamento das IFES. Em 2010, foram destinados R \$ 304 milhões.

Quanto às políticas públicas de inclusão, o governo aprovou o Estatuto da Igualdade Racial, a Lei $\mathrm{n}^{\circ}$ 12.288, de 20 de julho de 2010. Essa lei surge, no contexto das ações afirmativas, como medida legislativa de discriminação positiva, instituindo políticas de integração social da população negra. Reforça, 
para tanto, direitos fundamentais já previstos de forma genérica na Constituição Federal, dedicando um título inteiro às especificações de direitos da população negra, com destaque para prerrogativas como saúde, educação, esporte, cultura, lazer, liberdade de consciência e crenças religiosas, acesso à terra e à moradia adequada, trabalho e participação ativa nos meios de comunicação.

Em 2011, o Governo Dilma Rousseff lança o Plano Nacional dos Direitos da Pessoa com Deficiência - Viver sem Limite, sob Decreto $n^{0} 7.612 / 2011$, ressaltando o compromisso do Brasil com as prerrogativas da Convenção sobre os Direitos das Pessoas com Deficiência, da ONU, ratificada pelo nosso país com equivalência de emenda constitucional.

A justificativa do Viver sem Limite preconiza que o Brasil tem avançado na implementação dos apoios necessários ao pleno e efetivo exercício da capacidade legal por todas e cada uma das pessoas com deficiência. Isso quer dizer que cada vez o país tem se empenhado na equiparação de oportunidades para que a deficiência não seja utilizada como motivo de impedimento à realização dos projetos das pessoas, valorizando e estimulando o protagonismo e as escolhas das brasileiras e dos brasileiros com e sem deficiência. (BRASIL, 2011).

Segundo o Censo do IBGE/2010, atualmente, no Brasil, 45 milhões de pessoas declaram possuir algum tipo de deficiência. A proposta do Viver sem Limite é de que o governo federal, Distrito Federal, estados e municípios façam com que a Convenção sobre os Direitos das Pessoas com Deficiência se efetive na vida das pessoas por meio da articulação de políticas governamentais de acesso à educação, inclusão social, atenção à saúde e acessibilidade.

O Plano Viver sem Limite foi elaborado com a participação de mais de quinze ministérios e do Conselho Nacional dos Direitos da Pessoa com Deficiência (CONADE), que trouxe as contribuições da sociedade civil. O Plano Viver sem Limite envolveu todos os entes federados com um investimento total no valor de R \$ 7,6 bilhões até 2014. (BRASIL, 2013).

Com a publicação do Decreto $\mathrm{n}^{\circ} 7.612 / 2011$, que instituiu o Plano Viver sem Limite, muitos editais de fomento e incentivos à adequação e à promoção da acessibilidade vêm surgindo com mais força, nesse movimento, muito se tem comentando sobre o desenvolvimento de Tecnologias Assistivas (TA).

\section{O Programa Incluir como estratégia de permanência}

Para estudar o Programa Incluir, primeiro investigamos o contexto social no qual o mesmo está inserido, assim como os antecedentes históricos, políticos 
e sociais que o constituíram. Esse procedimento é importante para analisar as políticas públicas concernentes ao acesso e à permanência das pessoas com deficiência na educação superior. Também se destacará os conceitos deficiência, de pessoas com deficiência e pessoas com necessidades educacionais especiais, para entender a diferença dos atendimentos nos Núcleos de Acessibilidade.

Com relação à definição da condição de pessoa com deficiência, o Ministério da Educação (MEC), no documento Política Nacional de Educação Especial na Perspectiva da Educação Inclusiva, afirma que:

Consideram-se alunos com deficiência àqueles que têm impedimento de longo prazo, de natureza física, mental, intelectual ou sensorial, que em interação com diversas barreiras podem ter restringidas sua participação plena e efetiva na escola e na sociedade (BRASIL, 2008).

Salvaguardando outra concepção, Beyer (2010, p. 24) considera que “[...] a deficiência deve ser interpretada como uma realidade de indivíduos concretos, inseridos num contexto social, que apresenta suas relações e contradições". A identificação das condições sociais e econômicas da pessoa com deficiência é fundamental para a compreensão de uma condição determinada pelos elementos descritos. Nesta concepção pontua Padilha (2011, p. 22):

[...] deficiência não é uma insuficiência, mas uma organização peculiar das funções psicológicas superiores cuja configuração muda em conjuntos regulares de processos de significação, os quais diferem mais ou menos de processos normais e de tendências que a língua manifesta e pode suportar para ser interpretável.

Os conceitos pensados por Beyer (2010) e, sobretudo, Padilha (2011) representam a compreensão de que a condição de deficiência é determinada por múltiplos fatores e não representa, diretamente, uma característica de limite, mas uma condição específica que precisa ser compreendida para então ser interpretada.

A Política Nacional de Educação Especial na Perspectiva da Educação Inclusiva, publicada em 2008, define a população atendida pelos serviços de apoio da Educação Especial, que consiste no público-alvo do Programa Incluir: pessoas com deficiência, pessoas com altas habilidades e pessoas com transtorno 
global do desenvolvimento. O conceito de deficiência, definido por Padilha, determina outras possibilidades de compreensão do sujeito que aprende.

A Constituição Federal garante o direito à igualdade (art. $5^{\circ}$ ) e o direito de todos à educação (art. 205), tendo como princípio do ensino a igualdade de condições para o acesso e a permanência às instituições educacionais (art. 206, inc. I), garantindo acesso aos níveis mais elevados do ensino, da pesquisa e da criação artística, segundo a capacidade de cada um (art. 208, inc. V) (BRASIL, 1988). Porém, a legislação específica para garantir o acesso e a participação das pessoas com deficiência nos cursos de nível superior, assim como em outros espaços sociais, surgiu apenas nos últimos anos.

A Lei de Diretrizes e Bases da Educação Nacional (LDB), nº 9.394/1996, no seu art. 58, estabeleceu a dicotomia entre ensino regular e ensino especial, criando a modalidade de Educação Especial. Esta modalidade perpassa todas as etapas da educação brasileira: da educação infantil a educação superior.

A Portaria n ${ }^{\circ} 1.679$, de 1999, do Ministério da Educação, dispõe sobre requisitos de acessibilidade para pessoas com deficiência nos cursos superiores. No art. $1^{\circ}$ é assegurado que sejam incluídos requisitos de acessibilidade para alunos com deficiência: física, visual, auditiva, nos instrumentos de avaliação dos cursos superiores para efeito de autorização, reconhecimento, credenciamento e renovação de instituições de educação superior.

A Política Nacional para a Integração da Pessoa Portadora de Deficiência foi regulamentada pelo Decreto $n^{0} 3.298$, de 20 de dezembro de 1999, e objetivava integrar as ações dos órgãos e entidades públicas e privadas nas áreas de saúde, educação, cultura, desporto, lazer, trabalho, transporte, assistência social, edificação pública, previdência social e habitação, visando à prevenção das deficiências, à eliminação de suas múltiplas causas e à inclusão social. No que se refere à educação superior, tal Decreto (BRASIL, 1999), em seu art. 27, estabeleceu que as instituições de educação superior deverão: “[...] oferecer adaptações de provas e os apoios necessários, previamente solicitado pelo aluno portador de deficiência, inclusive tempo adicional para a realização das provas, conforme as características da deficiência".

O Programa Incluir é voltado exclusivamente para as instituições públicas federais de educação superior e foi desenvolvido pela Secretaria de Educação Superior (Sesu) e Secretaria de Educação Especial (Seesp), hoje do Ministério da Educação (MEC), tendo como objetivo básico promover o cumprimento do Decreto $\mathrm{n}^{\circ} 5.296 / 2004$. Uma das justificativas, da pertinência do programa, é o fato de $14,4 \%$ de a população brasileira apresentar algum tipo de deficiência que, em números absolutos, significa 24,5 milhões de habitantes. (BRASIL, 2013).

O Incluir tem como principal objetivo fomentar a criação e a consolidação de Núcleos de Acessibilidade nas IFES, os quais respondem pela organização de 
ações institucionais que garantam a integração de pessoas com deficiência à vida acadêmica, eliminando barreiras comportamentais, pedagógicas, arquitetônicas e de comunicação. De 2005 a 2010, o programa lançou editais com a finalidade de apoiar projetos de criação ou reestruturação desses núcleos nas IFES. Os núcleos melhoram o acesso das pessoas com deficiência a todos os espaços, ambientes, ações e processos desenvolvidos na instituição, buscando integrar e articular as demais atividades para a inclusão educacional e social dessas pessoas. Foram recebidas propostas de universidades do Brasil inteiro, mas somente as que atenderam às exigências do programa foram selecionadas para receber o apoio financeiro do MEC.

Os editais foram abertos à seleção pública para as instituições federais de educação superior, para apoio financeiro a programas ou projetos que visassem à inclusão de pessoas com deficiência na educação superior. Nos anos subsequentes foram publicados outros editais, com o objetivo de ampliar o número de instituições e aprimorar os projetos já aprovados nas IFES. No primeiro edital, em 2005, foram aprovados 13 projetos de inclusão nas instituições públicas de educação superior. No segundo edital, em 2006, 28 universidades foram contempladas. Em 2007, 38 universidades tiveram projetos aprovados. Em 2008, 36 projetos de inclusão foram aprovados. Em 2009, 40 universidades tiveram projetos aprovados. No edital de 2010, 44 instituições tiveram projetos aprovados. No total foram 199 projetos de inclusão na educação superior aprovados pelos editais do Programa Incluir.

No Governo de Dilma Rousseff, o Programa Incluir passou por uma nova reconfiguração, e, desde 2012, os recursos são repassados diretamente às universidades por meio dos Núcleos de Acessibilidade. O valor destinado a cada uma é proporcional ao número de alunos. Os Núcleos de Acessibilidade respondem pela organização de ações institucionais que garantam a integração de pessoas com deficiência à vida acadêmica, eliminando barreiras comportamentais, pedagógicas, arquitetônicas e de comunicação.

Vários núcleos de apoio à pessoa com deficiência, vinculados às instituições de educação superior no Brasil (IES), estão desenvolvendo suas atividades, tais como: USP Legal, Núcleo dos Direitos da USP; Núcleo de Informática na Educação Especial (NIEE) da UFRGS; Projetos de Acessibilidade do Núcleo de Computação Eletrônica (NCE)/UFRJ; Núcleo de Acessibilidade da UFSCar; Núcleo de Acessibilidade da UFG; Núcleo de Acessibilidade e Inclusão (NAIS) da UFF; Núcleo de Educação Inclusiva da UFOP; Núcleo de Apoio à Inclusão do Aluno com Necessidades Educacionais Especiais (NAI) da PUC/Minas; Núcleo de Estudos em Políticas de Inclusão Escolar (NEPIE) da UFRGS; Núcleos de Apoio às Pessoas Especiais (NAPE) da UFBA etc.

Para Cury (2005), políticas inclusivas supõem uma adequação efetiva ao conceito avançado de cidadania, coberto pelo ordenamento jurídico do país. 
É ainda dentro dos espaços nacionais, espectro privilegiado da cidadania, que se constroem políticas duradouras, em vista de uma democratização de bens sociais, aí compreendida a educação escolar.

A concepção da educação inclusiva requer uma mudança nas práticas, de modo a atender a todos os alunos, sem qualquer tipo de discriminação, respeitando suas diferenças. Isso pressupõe a adequação ao conceito de escola inclusiva, de acordo com as Diretrizes Nacionais para a Educação Especial. (BRASIL, 2001). Implica, também, em uma nova postura da escola regular, que deve propor ações que favoreçam a inclusão e práticas educacionais diferenciadas que atendam a todos os alunos.

Dessa forma, podemos observar a crescente inquietação das instituições de educação superior na busca de alternativas para dar conta da permanência desses alunos, no contexto da universidade, com a implantação de programas de apoio para os alunos com deficiências, apoiado nas políticas de ações afirmativas do $\mathrm{MEC}$, como programas de apoio às minorias, em geral, e, mais especificamente, o Programa Incluir. Além disso, alguns marcos legais, a exemplo da Portaria ${ }^{\circ}$ 3.284/2003, que estabelecem as condições de acessibilidade para o reconhecimento de cursos de graduação, também têm contribuído para uma perspectiva inclusiva na educação superior.

\section{Considerações finais}

Podemos observar que as universidades nacionais ampliam as ações de permanência destinadas aos estudantes com deficiência. $\mathrm{O}$ incentivo e financiamento a essas ações têm como principal referência o Programa Incluir, mas também se materializam por meio de políticas destinadas a ações afirmativas e outras que priorizam grupos específicos, muitas vezes identificados como minorias. No entanto, são vários os limites do Programa e dos Núcleos de Acessibilidade que os impedem de atingir muitos dos seus objetivos propostos, como ser um programa que garanta a permanência do aluno com deficiência na educação superior. O governo não dialogou com a comunidade acadêmica sobre a inclusão das pessoas com deficiência e suas reais necessidades; o programa não considerou as especificidades das pessoas com deficiência, nem as universidades receberam formação para a implantação dos núcleos; não considerou as iniciativas existentes em algumas IES; não contemplou todas as IES do país, apenas as públicas federais, sendo que os maiores programas de acesso e permanência como o FIES e o PROUNI são para as privadas; os professores 
não foram capacitados para receber esses novos acadêmicos, pois a maioria não desenvolve programas ou projetos de apoio a estes; o financiamento do governo é insuficiente.

É fato que novos caminhos e novas formas para implementar projetos e ações práticas que garantam o atendimento à educação inclusiva já começam a ser discutidos e construídos por várias instituições e professores. À universidade cabe desempenhar o papel social, e aos órgãos competentes assumir totalmente as ações para garantir o acesso e a permanência de todas as pessoas à educação superior.

O Programa Incluir representa uma das possibilidades para favorecer o acesso e a permanência de pessoas com deficiência na educação superior, entretanto, consiste parte das ações na perspectiva da inclusão em um sistema capitalista.

\section{REFERÊNCIAS}

BEYER, H. O. Inclusão e Avaliação na Escola. 3. ed. Porto Alegre: Mediação, 2010.

BITTAR, M.; MOROSINI, M. C. Enciclopédia de pedagogia universitária: glossário. Vol. 2. Editora-chefe: Marília Costa Morosini. Brasília: Instituto Nacional de Estudos e Pesquisas Educacionais Anísio Teixeira, 2006.

BIANCHETTI, R. G. Modelo neoliberal e políticas educacionais. 4. ed. São Paulo: Cortez, 2005.

BOBBIO, N. Liberalismo e democracia. 6. ed. Tradução de Marco Aurélio Nogueira. São Paulo: Brasiliense, 2005.

BRASIL. Constituição da República Federativa do Brasil. Brasília: Senado Federal, 1988.

BRASIL. Lei Federal no 9.394, de 20 de dezembro 1996. Estabelece as diretrizes e bases da educação nacional. Diário Oficial da União. Brasília, DF, 20 dez. 1996. Disponível em: <http://www.planalto.gov.br/ccivil_03/LEIS/19394.htm>. Acesso em: 20 set. 2012.

BRASIL. Decreto $n^{\circ} 3.298$, de 20 de dezembro de 1999. Regulamenta a Lei ${ }^{\circ} 7.853$, de 24 de outubro de 1989, dispõe sobre a Política Nacional para a Integração da Pessoa Portadora de Deficiência, consolida as normas de proteção e dá outras providências. Disponível em: <http://www.planalto.gov.br/ccivil_03/decreto/d3298.htm>. Acesso em: 03 maio 2015.

BRASIL. Decreto $n^{\circ} 3.956$, de 8 de outubro de 2001. Promulga a Convenção Interamericana para a Eliminação de Todas as Formas de Discriminação contra as Pessoas Portadoras de Deficiência. Guatemala, 2001a. 
BRASIL. Lei no 10.172 , de 9 de janeiro de 2001. Aprova o Plano Nacional de Educação e dá outras providências. Diário Oficial da União, Brasília/DF, 10 jan. 2001b.

BRASIL. Ministério da Educação. Resolução $C N E / C E B N^{o}$ 2, de 11 de setembro de 2001. Institui Diretrizes Nacionais para a Educação Especial na Educação Básica. 2001c. Disponível em: < http://portal.mec.gov.br/cne/arquivos/pdf/CEB0201.pdf>. Acesso em: 15 maio 2014.

BRASIL. Decreto ${ }^{\circ} 5.296$, de 2 de dezembro de 2004. Regulamenta as Leis $n^{\circ}{ }^{\circ}$ 10.048, de 8 de novembro de 2000, que dá prioridade de atendimento às pessoas que especifica, e 10.098, de 19 de dezembro de 2000, que estabelece normas gerais e critérios básicos para a promoção da acessibilidade das pessoas portadoras de deficiência ou com mobilidade reduzida, e dá outras providências. Diário Oficial da União, Brasília/DF, 3 dez. 2004.

BRASIL. Edital no 8. Programa Incluir. Diário Oficial da União, n. 126, seção 3, Brasília, DF, 4 jul. 2006, p. 30-31. Disponível em: <http:/www.in.gov.br/visualiza/ index.jsp?d ata $=04 / 07 / 2006 \&$ jornal $=3 \&$ pagina $=30 \&$ totalArquivos $=120>$. Acesso em: 15 set. 2012 .

BRASIL. Ministério da Educação. Política Nacional de Educação Especial na Perspectiva da Educação Inclusiva. Brasília/DF, 2008. Disponível em: <http://portal.mec. gov. br/arquivos/pdf/politicaeducespecial.pdf $>$. Acesso em: 20 jan. 2013.

BRASIL. Decreto $n^{\circ} 7.612$, de 17 de novembro de 2011. Institui Plano Nacional dos Direitos da Pessoa com Deficiência - Plano Viver sem Limite. Diário Oficial da União, Brasília, DF, 18 nov. 2011. Disponível em: < http://www.planalto.gov.br/ccivil 03/_ato2011-2014/2011/decreto/d7612.htm>. Acesso em: 23 maio 2013.

BRASIL. Ministério da Educação. Documento orientador Programa Incluir-Acessibilidade na Educação Superior. Secadi/Sesu-2013. Brasília/DF, 2013. Disponível em: $<$ http:// portal/ mec.gov.br/arquivos/pdf/politicaeducespecial.pdf>. Acesso em: 10 maio 2013.

CARVAlHO, S. M. C. R. Representação social da pessoa com deficiência frente à exclusão/inclusão. Dissertação (Mestrado em Educação) - Universidade Federal da Paraíba, João Pessoa, Paraíba. 2010.

CURY, R. J. Gestão democrática dos sistemas públicos de ensino. In: OLIVEIRA, M. A. M. Gestão educacional: novos olhares, novas abordagens. Petrópolis: Vozes, 2005.

HAYEK, F. O caminho da servidão. Tradução de Leonel Valandro. 2. ed. Porto Alegre: Globo, 1994.

PADILHA, A. M. L. Práticas Pedagógicas na Educação Especial: a capacidade de significar o mundo e a inserção cultural do deficiente mental. 3. ed. Campinas: Editora Autores Associados, 2011.

Texto recebido em 31 de maio de 2017. Texto aprovado em 10 de junho de 2017. 